\title{
Sentinel lymph node biopsy using dye alone method is reliable and accurate even after neo-adjuvant chemotherapy in locally advanced breast cancer - a prospective study
}

\author{
Chintamani ${ }^{1,2^{*}}$, Megha Tandon ${ }^{1,2}$, Ashwani Mishra ${ }^{2,3}$, Usha Agarwal ${ }^{2,3}$, Sunita Saxena ${ }^{2,3}$
}

\begin{abstract}
Background: Sentinel lymph node biopsy (SLNB) is now considered a standard of care in early breast cancers with NO axillae; however, its role in locally advanced breast cancer (LABC) after neo-adjuvant chemotherapy (NACT) is still being debated. The present study assessed the feasibility, efficacy and accuracy of sentinel lymph node biopsy (SLNB) using "dye alone" (methylene blue) method in patients with LABC following NACT.

Materials and methods: Thirty, biopsy proven cases of $\angle A B C$ that had received three cycles of neo-adjuvant chemotherapy (cyclophosphamide, adriamycin, 5-fluorouracil) were subjected to SLNB (using methylene blue dye) followed by complete axillary lymph node dissection (levels I-III). The sentinel node(s) was/were and the axilla were individually assessed histologically. The SLN accuracy parameters were calculated employing standard definitions. The SLN identification rate in the present study was $100 \%$. The sensitivity of SLNB was $86.6 \%$ while the accuracy was $93.3 \%$, which were comparable with other studies done using dual lymphatic mapping method. The SLN was found at level I in all cases and no untoward reaction to methylene blue dye was observed.

Conclusions: This study confirms that SLNB using methylene blue dye as a sole mapping agent is reasonably safe and almost as accurate as dual agent mapping method. It is likely that in the near future, SLNB may become the standard of care and provide a less morbid alternative to routine axillary lymph node dissection even in patients with $L A B C$ that have received NACT.
\end{abstract}

\section{Introduction}

Breast cancer is the most common site specific cancer in women and represents $20 \%$ of all female malignancies. In developing countries like India, $25-30 \%$ patients still present with locally advanced breast cancers (LABC). The current treatment guidelines for LABC focus upon multimodality approach i.e. neo-adjuvant chemotherapy (NACT) followed by surgery and adjuvant therapies in the form of chemotherapy, radiotherapy, hormone therapy etc. The well known advantages of NACT include, down staging and downsizing of the tumor to make it amenable to breast conservation surgery, as well as

\footnotetext{
* Correspondence: chintamani7@rediffmail.com

'Department of Surgery, Vardhman Mahavir Medical College, Safdarjang Hospital, New Delhi, 110023, India

Full list of author information is available at the end of the article
}

serving as an in-vivo test of sensitivity to the chemotherapy regimen used [1-3].

The histological status of axillary lymph nodes is one of the most important prognostic factors in patients with breast carcinoma and remains so, even after NACT $[1,2]$. NACT, initially introduced to downstage LABC to facilitate optimum surgery, results in an improved disease free survival and overall survival, which is comparable with the effects of adjuvant chemotherapy [4-7]. More recently, the indications for NACT have also been extended to selected patients with an early staged disease to allow breast conserving surgery $[8,9]$. Another potential advantage of NACT is the opportunity to observe chemosenstivity in vivo, providing prognostic information [10].

Whether sentinel lymph node biopsy (SLNB) is feasible and accurate following NACT is of significance, since

\section{C) Biomed Central}


axillary status gets down staged to N0 in considerable proportion of patients after NACT (30-40\%). Demonstrating the accuracy of SLNB in this setting can help a proportion of initially node positive patients that have been down staged to NO by avoiding the morbidity of routine axillary lymph node dissection. The aim of this study was to determine the accuracy of SLNB following NACT for LABC using methylene blue dye alone.

\section{Methods}

The study was conducted in the Department of Surgery, Vardhman Mahavir Medical College Safdarjang Hospital in collaboration with Indian Council of Medical Research, New Delhi, over a period of 1 year (from Dec 2008 to Jan 2009) after obtaining clearance from the "Institutional review Board" and the "Ethical Committee" of Safdarjang Hospital New Delhi India.

\section{Patients}

Thirty fine needle aspiration cytology (FNAC) confirmed cases of LABC (i.e. Stage IIb and stage III) were evaluated after taking informed consent for enrolment in the study. Ultrasonography (USG) and Magnetic resonance imaging (MRI) of both breasts were done for accurate measurement of the basal tumor size in order to stage the disease accurately. A core needle biopsy was routinely performed for baseline tumor marker status and assessing the grade. The FNAC was not used for the nodal metastases in the study. The patients were then subjected to blood and radiological investigations including an echocardiogram before initiation of neoadjuvant chemotherapy (NACT)that was administered in standard doses at three weekly intervals [Cyclophosphamide $500 \mathrm{mg} / \mathrm{m}^{2}$, Adriamycin $50 \mathrm{mg} / \mathrm{m}^{2}$ (methotrexate in cardiotoxic patients) and 5 -FU $\left.500 \mathrm{mg} / \mathrm{m}^{2}\right]$. All cases were re-assessed clinically and with ultrasonography and MRI of the breast (using RECIST criteria) for response assessment after each cycle.

After 3 weeks of the last cycle of NACT, the patients were taken up for surgery i.e. modified radical mastectomy (MRM) with a standardized technique by the same surgical team. Intra-operatively peri-tumoral injections of 2-3 $\mathrm{ml}$ of methylene blue dye were given followed by breast massage for five minutes before the patient was being draped and prepared for surgery. The sentinel node/s (blue node/s) was mapped and isolated after raising the flaps (the average time taken for the dissection of sentinel node was 10 minutes after injection of the dye). Only nodes that were stained blue were considered as sentinel i.e. even an enlarged or firm axillary node which did not stain was not considered as sentinel. The average number of sentinel nodes removed ranged from one to four. The sentinel lymph node/s was/were sent in a separate container and was/were assessed for the presence of metastatic deposits and compared with the rest of the axillary lymph nodes. As a part of the modified radical mastectomy complete (level-I to level-III) axillary dissection was subsequently performed and the axillary lymph nodes were sent for histopathological evaluation. In all patients, a minimum of ten dissected lymph nodes were considered as optimum axillary dissection.

\section{Statistical analysis}

Thirty patients of locally advanced breast carcinoma were studied using descriptive statistics. The Mc Nemar's Chi square test and paired $\mathrm{T}$ test were used to determine association between two variables. $P$ value less than or equal to 0.05 was taken as significant.

The values of the diagnostic parameters related to techniques of SLNB were estimated in terms of sensitivity, specificity, positive predictive value, negative predictive value, false negative rate and accuracy on the basis of distribution of 30 cases into four categories of SLN and axilla expression patterns.

Data analysis was performed by SPSS version 11.5 .

\section{Results}

All 30 cases were of locally advanced carcinoma (i.e. stage IIb and stage III). The age of the patients ranged from 32-85 years with a mean age of 47.3 years and a standard deviation of 10.98 years (Table 1 ). Majority of the patients were post-menopausal (20 out of 30 patients i.e. $66.6 \%$ ).

The distribution of tumor size before and after NACT is shown in Table 2.

Using the paired t-test for significance, with 95\% confidence limits, $(\mathrm{p}<0.001)$ the difference in the pre and post neo-adjuvant chemotherapy tumor size was found to be statistically significant.

$56.70 \%$ of the patients in our study had clinically N2 disease (fixed ipsilateral axillary nodes), which was in direct correlation with the large tumor size and advanced stage of the disease. However none of the patients had N0 or N3 axilla. After NACT most of the patients were down staged with respect to their axillary lymph node status, with about half $(50 \%)$ of them having no clinical/sonological/MRI) evidence of lymphadenopathy following NACT (Table 3).

\section{Table 1 Group wise age distribution}

\begin{tabular}{lll}
\hline Age (years) & No. of patients & Percentage \\
\hline $\mathbf{3 1 - 4 0}$ & 10 & $33.3 \%$ \\
\hline $\mathbf{4 1 - 5 0}$ & 12 & $40 \%$ \\
\hline $\mathbf{5 1 - 6 0}$ & 5 & $16.6 \%$ \\
\hline $\mathbf{6 1 - 7 0}$ & 3 & $10 \%$ \\
\hline $\mathbf{7 1 - 8 0}$ & 0 & $0 \%$ \\
\hline $\mathbf{8 1 - 9 0}$ & 1 & $3.33 \%$ \\
\hline
\end{tabular}


Table 2 Pre NACT vs. Post NACT tumor Size

\begin{tabular}{lllll}
\hline & & Mean & N & Std. Deviation \\
\hline \multirow{3}{*}{ Tumor } & Pre NACT & 6.31 & 30 & 2.4 \\
\cline { 2 - 5 } & Post NACT & 3.44 & 30 & 1.9 \\
\hline
\end{tabular}

Out of 14 patients that were N1 before NACT, 9 (64.31\%) were down staged to N0, while in 5(35.70\%) patients axillary status remained at N1. Out of total 16 patients that were $\mathrm{N} 2$ before NACT, 6(37.4\%) were down staged to N0. 5(31.3\%) were down staged to N1, while in $5(31.3 \%)$ patients there was no change in axillary status.

Using the chi square test $(\mathrm{p}=0.049)$, the difference in pre and post chemotherapy lymph node status was found to be statistically significant.

Relationship of sentinel lymph node biopsy and axillary status is summarized in the Tables 4 \& 5

In 13 patients $(n=30)$ the SLN and the axilla were both positive for the disease while in 2 patients (6.6\%), the SLN was negative while the axilla was positive (indicating that the SLNB could not accurately predict the axillary status). In 15 patients $(50 \%, \mathrm{n}=30)$ both the SLN and the axilla were negative and the SLNB could accurately predict the status of the axilla.

In all patients sentinel lymph node/s was at level I (lateral to Pectoralis minor)

Following parameters were calculated by applying basic descriptive statistical methods:

Sensitivity of SLN = True positives/(true positives + false negatives)

Was found to be $=86.67 \%$

False negative rate $=$ False negatives $/$ false negatives +true positives)

Was found to be $=13.33 \%$

Negative predictive value $=$ True negative $/$ true negative + false negative)

Was found to be $=88.23 \%$
Accuracy $=$ True positive + True negative $/$ No. of patients with successfully identified SLN

Was found to be $=93.30 \%$

Sentinel lymph node accuracy parameters were calculated according to standard definitions, used in various studies on sentinel lymph node/s (SLN) and they were as follows:

- The Identification Rate was defined as the number of patients who underwent a successful SLN biopsy divided by total number of patients in whom a SLN biopsy was attempted. The identification rate in the present study was $\mathbf{1 0 0 \%}$ i.e. SLN could be identified in all thirty patients included in the study.

- The results from each successfully identified SLN were categorized as true positives, true negatives, or false negatives, taking the outcome of the complete ALND as "reference standard".

- A true negative SLN was defined in this study as a negative SLN and a negative axilla after ALND. The true negatives SLN in the present study were $15(50 \%)$. - A false negative SLN was defined as negative SLN with positive lymph nodes in ALND. There were 2 false negative cases in the present study, out of a total of 15 cases that had a positive axilla after ALND. Of the two "false negative cases", one was a "non responder" that was N2 (both pre and post $\mathrm{NACT}$ ) and the other was a responder (pre NACT-N2 and post NACT-N1) i.e. Both false negative cases were not $\mathrm{NO}$ after three cycles of NACT. $50 \%$ cases i.e. 15/30 cases in our study were down staged from N1 or N2 to N0.

- A true positive SLN was defined as a positive SLN with or without a positive axilla and in this study $\mathbf{1 3}$ cases were true positives.

Based on these definitions, there were no false positive cases in this study.

Accuracy was computed as the sum of all true positives and true negatives, divided by the total number of

Table 3 Lymph Node status before and after NACT Cross tabulation

\begin{tabular}{|c|c|c|c|c|c|c|}
\hline & & & \multicolumn{3}{|c|}{ Post NACT lymph nodes } & \multirow[t]{2}{*}{ Total } \\
\hline & & & NO & N1 & N2 & \\
\hline & N1 & Count & 9 & 5 & 0 & 14 \\
\hline & & $\%$ within Pre NACT lymph node & $64.3 \%$ & $35.7 \%$ & 0 & $100 \%$ \\
\hline \multirow[t]{2}{*}{ Pre NACT lymph nodes } & N2 & Count & 6 & 5 & 5 & 16 \\
\hline & & $\%$ within Pre NACT lymph node & $37.4 \%$ & $31.3 \%$ & $31.3 \%$ & $100 \%$ \\
\hline \multirow[t]{2}{*}{ Total } & & Count & 15 & 10 & 5 & 30 \\
\hline & & \% within Pre NACT Iymph node & $50 \%$ & $33.3 \%$ & $16.7 \%$ & $100 \%$ \\
\hline
\end{tabular}


Table 4 Relationship of sentinel lymph node biopsy and axillary status

\begin{tabular}{lll}
\hline & \multicolumn{2}{l}{ Axilla(n= 30) } \\
\cline { 2 - 3 } Sentinel lymph node & Positive & Negative \\
\hline \hline Positive & $13(43.3 \%)$ & $0(0 \%)$ \\
\hline Negative & $2(6.6 \%)$ & $15(50 \%)$ \\
\hline
\end{tabular}

patients with a successfully identified SLN. Accuracy in this study was $\mathbf{9 3 . 3 1 \%}$.

\section{Discussion}

The histological status of axillary lymph nodes is one of the most important prognostic factors in patients with breast carcinoma and remains so, even after NACT $[1,2]$. NACT, initially introduced to downstage LABC to facilitate optimum surgery, also results in an improved disease free survival and overall survival, which is comparable with the effects of adjuvant chemotherapy [4-7]. More recently, the indications for NACT have also been extended to selected patients with an early staged disease to allow breast conserving surgery $[8,9]$. Another potential advantage of NACT is the opportunity to observe chemosenstivity in vivo, providing vital prognostic information [10].

Following NACT, traditionally ALND is performed as a part of optimum breast surgery. This however is associated with considerable morbidity $[11,12]$. A less aggressive approach is therefore sought for, making SLNB after NACT an attractive strategy as the axilla is downstaged to N0 in a number of patients $(20-40 \%)[8,13]$. In concordance with the established data, the nodal down staging in the present study was about $50 \%$ (in the present study, 9 out of $14 \mathrm{~N} 1$ and 6 of $16 \mathrm{~N} 2$ patients were down staged to N0 i.e. $15 / 30$ patients). Thus considerable number of patients could be spared the morbidity of ALND, once the SLNB gets established as a standard of care in patients with LABC after NACT.

Theoretically, NACT could have several negative effects on the accuracy of the SLN biopsy. Firstly, both

Table 5 SLNB results by post-NACT axillary status $(n=$ 30)

\begin{tabular}{ccccccc}
\hline \multirow{2}{*}{ SLNB } & \multicolumn{6}{c}{ POST NACT AXILLARY STATUS } \\
\cline { 2 - 7 } & N0 $=\mathbf{1 5}$ & \multicolumn{2}{c}{ N1 = 10 } & \multicolumn{2}{c}{ N2 = 5 } \\
\cline { 2 - 7 } & + ve & -ve & +ve & -ve & +ve & -ve \\
\hline +ve & 3 & 3 & 4 & 0 & 2 & 1 \\
\hline -ve & 0 & 9 & 1 & 5 & 1 & 1
\end{tabular}

No, N1, N2 is the pre-operative lymph node status, i.e. after NACT, while + represents the histopathological report i.e. $\mathrm{pN}+/ \mathrm{pN}$ -

There were two "false negative cases", one was a "non responder" that was N2 (both pre and post NACT) and the other was a responder (pre NACT-N2 and post NACT-N1) i.e. both false negative cases cases were not N0 after three cycles of NACT. 50\% cases i.e. 15/30 cases in our study were down staged from $\mathrm{N} 1$ or $\mathrm{N} 2$ to N0. primary tumor and metastatic lymph nodes respond by yielding reactive changes like fibrosis affecting the lymphatic drainage patterns. Secondly, chemotherapy can induce an uneven tumor response in axilla. These effects are likely to result in decreased SLNB accuracy after NACT. It has been observed in various studies (Table 6) that there could be a reduction in the identification rates without a significant drop in the predictive value of SLNB even after NACT [14-18]. The accuracy and false negative rates of sentinel lymph node biopsy after NACT were found to be comparable with those of other multicenter trials of SNB (without NACT) and the present study also highlights the same [14-18]. The false negative rates in the present study were $13.3 \%$, favorably comparable with those of (7-13\%) in SNB studies before NACT, suggesting that the apprehension regarding skip nodal metastasis could be over-rated and that the SLNB remains almost equally reliable.

When comparing SLNB success rates amongst heterogeneous studies (i.e. between studies including patients treated with NACT vs. those including patients that have not received NACT), one must take into account the fact that false negative rates depend on the probability of nodal involvement. Among the patients with lower probability of nodal involvement, there is more variation in the false negative rates because the sample size would be smaller [18]. The various single institutional studies evaluating SNB after NACT with their results are summarized in Table 7 .

The largest cohort study till date evaluating SNB after NACT was NSABP B-27 multi-centric randomized trial $(\mathrm{N}=428)$, reported an identification rate, a false negative rate and accuracy of $85 \%, 11 \%$, and $96 \%$ respectively but the locally advanced breast cancers were not included in this study [14]. The overall success rates for sentinel node identification were $84.4 \%$ which were similar to results from other single institutional studies [19-26]. This study also concluded that these rates are comparable to those obtained from other multi-centric studies evaluating SLNB and suggested that SLNB is feasible and reliable following NACT. This was also observed in the meta-analysis by Xing and colleagues [15]. In the present study, an identification rate of $100 \%$, false negative rates of $13.30 \%$ and accuracy of $93.31 \%$ were achieved. The rates do not differ substantially from prior multi-centric studies evaluating sentinel node success rates without NACT, that have reported an identification rate of $88-97 \%$ and false negative rates of $5-10 \%$.

As summarized in Table 7, various single institutional studies have examined the efficacy of SLNB after NACT in patients with operable as well as locally advanced breast cancers and reported an identification rates between 84 and 94\% [19-21]. All these studies report a higher identification rates when the dual mapping 
Table 6 Comparison of identification rates and false negative rates between NSABP-SNB after NACT trial B-27 and three multicenter studies of SNB following breast cancer diagnosis [14-18]

\begin{tabular}{|c|c|c|c|c|c|}
\hline Author & Study Design & $\begin{array}{l}\text { No. of } \\
\text { patients }\end{array}$ & $\begin{array}{l}\text { Type of lymphatic } \\
\text { mapping }\end{array}$ & $\begin{array}{l}\text { Identification } \\
\text { rate } \%\end{array}$ & $\begin{array}{l}\text { False } \\
\text { negative } \\
\text { rate } \%\end{array}$ \\
\hline $\begin{array}{l}\text { Mamounas } \\
\text { et al [14] }\end{array}$ & $\begin{array}{l}\text { Multicenter SNB } \\
\text { after NACT }\end{array}$ & 428 & $\begin{array}{l}\text { Blue dye Radiocolloid } \\
\text { Combination All techniques }\end{array}$ & $\begin{array}{l}78 \\
89 \\
88 \\
85\end{array}$ & $\begin{array}{l}14 \\
05 \\
09 \\
11\end{array}$ \\
\hline Krag et al [16] & $\begin{array}{l}\text { Multicenter SNB before } \\
\text { systemic therapy }\end{array}$ & 443 & Radiocolloid & 93 & 11 \\
\hline Tafra et al [17] & $\begin{array}{l}\text { Multicenter SNB before } \\
\text { systemic therapy }\end{array}$ & 529 & $\begin{array}{l}\text { Combination of blue dye } \\
\text { and radiocolloid }\end{array}$ & 87 & 13 \\
\hline $\begin{array}{l}\text { Mc Masters } \\
\text { et al [18] }\end{array}$ & $\begin{array}{l}\text { Multicenter SNB before } \\
\text { systemic therapy }\end{array}$ & 806 & $\begin{array}{l}\text { Single agent (blue dye or radio colloid) } \\
\text { Combination All techniques }\end{array}$ & $\begin{array}{l}86 \\
90 \\
88\end{array}$ & $\begin{array}{l}12 \\
6 \\
7\end{array}$ \\
\hline
\end{tabular}

method (i.e. radio-active colloid in combination with blue dye) was used rather than any of the methods used alone. The identification rate in the present study was $100 \%$ using the methylene blue dye alone and all the lymph nodes were identified at level-I, highlighting that even after NACT, lymphatic drainage remained more or less predictable [19-25].

The false negative rates in these studies were quiet variable (0-33\%), leading to different conclusions about the accuracy of the procedure in this setting. However the small size of these studies can easily account for the wide variability of the estimates. When one examines all these studies after combining the outcomes, the false negative rates would be $12.5 \%$, comparable to our experience and also to the rates seen in studies of SNB before NACT. The false negative rates in our study were $13.30 \%$. There were two "false negative cases", one was a "non responder" that was N2 (both pre and post NACT) and the other was a responder (pre
NACT-N2 and post NACT-N1) i.e. both false negative cases were not NO after three cycles of NACT. Half the cases $(50 \%)$ in the present study were down staged from N1 or N2 to No.

There are several limitations as well as strengths in the present study. Limitations include smaller size and higher variability in the age distribution of the cohort. Strengths include the fact that the data was collected prospectively and the same operating team ensured that there was a uniform procedure for lymphatic mapping. There was also a standardized procedure for pathological assessment of the SLN and the axilla by a single team.

\section{Conclusions}

The present study confirms the observations of various other studies in the literature that sentinel lymph node biopsy is feasible and reliable even in locally advanced carcinoma after NACT. The possibility of skip metastasis is perhaps an exaggerated apprehension. There is a high

Table 7 Single institution series evaluating SNB after NACT [19-25]

\begin{tabular}{|c|c|c|c|c|c|c|c|}
\hline Author & Stage & $\begin{array}{l}\text { Type of lymphatic } \\
\text { mapping }\end{array}$ & $\begin{array}{l}\text { All patients } \\
\text { (No.) }\end{array}$ & $\begin{array}{l}\text { Node positive } \\
\text { patients }\end{array}$ & $\begin{array}{l}\text { Success rate } \\
\%\end{array}$ & $\begin{array}{l}\text { False } \\
\text { negative } \\
\text { rate } \%\end{array}$ & $\begin{array}{l}\text { Conclusion } \\
\text { regarding } \\
\text { accuracy of } \\
\text { SLNB }\end{array}$ \\
\hline $\begin{array}{l}\text { Breslin TM et al } \\
{[19,20]}\end{array}$ & $\|/\| \|$ & $\begin{array}{l}\text { Blue dye+/_radio } \\
\text { colloids }\end{array}$ & 51 & 25 & 84.3 & 12 & Accurate \\
\hline Nason KS et al [21] & $\mathrm{T} 1-\mathrm{T} 4, \mathrm{~N} 0$ & Blue dye +radio colloid & 15 & 9 & 86.7 & 33 & Inaccurate \\
\hline Julien TB et al [22] & I/II, palpable & $\begin{array}{l}\text { Blue dye +/_- } \\
\text { radiocolloid }\end{array}$ & 31 & 6 & 93.5 & 0.0 & Accurate \\
\hline Steams V et al [23] & $\begin{array}{l}\text { Locally } \\
\text { advanced }\end{array}$ & Vital blue dye & 34 & 13 & 85.3 & 14.3 & Accurate \\
\hline Fernandez A [24] & T1-T4. N0-N1 & Radio-colloid & 40 & 16 & 85 & 25 & Inaccurate \\
\hline Haid A et al [25] & $\begin{array}{l}\text { T1-T3, } \\
\text { operable }\end{array}$ & Blue dye+ radiocolloid & 33 & 18 & 87.9 & 0.0 & Accurate \\
\hline Miller AR et al [26] & operable & $\begin{array}{l}\text { Radicolloid, blue dye, } \\
\text { both }\end{array}$ & 35 & 9 & 86 & 0.0 & Accurate \\
\hline $\begin{array}{l}\text { All studies } \\
\text { combined }\end{array}$ & & & 230 & 96 & 86 & 12.5 & \\
\hline
\end{tabular}


likelihood in near future of SLNB becoming the standard of care even in post NACT-N0 axillae in LABC. SLNB with methylene blue "dye alone" method used in the present study was found to be a cost effective, reliable and almost as accurate as dual agent mapping method to assess the status of axilla. Should SNB become established as the standard method for staging axilla, it will be reasonable to utilize this technique in LABC patients also that have received NACT, expanding the utility of both interventions.

\section{Acknowledgements}

Our gratitude to all our patients.

\section{Author details}

'Department of Surgery, Vardhman Mahavir Medical College, Safdarjang Hospital, New Delhi, 110023, India. ${ }^{2}$ Vardhman Mahavir Medical College, Safdarjang Hospital, New Delhi, 110023, India. Indian Council of Medical Research, Institute of Pathology, New Delhi, 110023, India.

\section{Authors' contributions}

C, MT, UA, AM and SS contributed to the designing of the study and preparation of manuscript. All authors read and approved the manuscript.

\section{Competing interests}

The authors declare that they have no competing interests.

Received: 15 July 2010 Accepted: 8 February 2011

Published: 8 February 2011

\section{References}

1. Cure H, Amat S, Penault-Llorca F, le Bouëdec G, Ferrière JP, MouretReynier MA, Kwiatkowski F, Feillel V, Dauplat J, Chollet P: Prognostic value of residual node involvement in operable breast cancer after induction chemotherapy. Breast Cancer res Treat 2002, 76:37-45.

2. Kuerer HM, Newman LA, Buzdar AU, Hunt KK, Dhingra K, Buchholz TA Binkley SM, Ames FC, Feig BW, Ross MI, Hortobagyi GN, Singletary SE: Residual metastatic axillary lymph nodes following neoadjuvant chemotherapy predict disease free survival in patients with locally advanced breast cancer. Am J Surg 1998, 176:502-9.

3. Rouzier R, Extra JM, Klijanienko J, Falcou MC, Asselain B, Vincent-Salomon A, Vielh $\mathrm{P}$, Bourstyn E: Incidence and prognostic signioficance of complete axillary downstaging after primary chemotherapy in breast cancer patients with $\mathrm{T} 1$ to $\mathrm{T} 3$ tumors and cytologically proven axillary metastatic lymph nodes. J Clin Oncol 2002, 20:1304-10.

4. Fisher B, Bryant J, Wolmark N, Mamounas E, Brown A, Fisher ER, Wickerham DL, Begovic M, DeCillis A, Robidoux A, Margolese RG, Cruz AB $J$ r, Hoehn JL, Lees AW, Dimitrov NV, Bear HD: Effect of pre-operative chemotherapy on the outcome of women with operable breast cancer. J Clin Oncol 1998, 16:2672-2685.

5. Van der Hage JA, Van de Velde CJ, Julien JP, Tubiana-Hulin M, Vandervelden C, Duchateau L, van der Hage JA, van de Velde CJ, Julien JP, Tubiana-Hulin M, Vandervelden C, Duchateau L: Preoperative chemotherapy in primary operable breast cancer: results from the European Organisation for Research and Treatment of Cancer trial 10902. J Clin Oncol 2002, 19:4224-37.

6. Mauri D, Pavlisdis N, loannidis JP: Neoadjuvant vs adjuvant systemic treatment in breast cancer: a meta-analysis. J Natl Cancer Inst 2005, 97:188-94.

7. Mieog JS, Van der Hage JA, Van de Velde CJ: Neoadjuvant chemotherapy for operable breast cancer. Br J Surg 2007, 94:1189-2000.

8. Fisher B, Brown A, Mamounas E, Wieand S, Robidoux A, Margolese RG, Cruz AB Jr, Fisher ER, Wickerham DL, Wolmark N, DeCillis A, Hoehn JL, Lees AW, Dimitrov NV: Effect of preoperative chemotherapy on loco-regional disease in women with operable breast cancer: findings from NSABP B-18. J Clin Oncol 1997, 15:2483-93.

9. Bonadonna G, Veronesi U, Brambilla C, Ferrari L, Luini A, Greco M, Bartoli C, Coopmans de Yoldi G, Zucali R, Rilke F: Primary chemotherapy to avoid mastectomy in tumors with diameters of three centimeters or more. J Natl Cancer Inst 1990, 82:1539-45.

10. Fisher B, Mamounas EP: Preoperative chemotherapy: a model for studying the biology and therapy of primary breast cancer. $J$ Clin Oncol 1995, 13:537-40.

11. Rietman JS, Dijkstra PU, Geertzen JH, Baas P, de Vries J, Dolsma W, Groothoff JW, Eisma WH, Hoekstra HJl: Treatment related upper limb morbidity 1 year after sentinel node biopsy or axillary lymph node dissection for stage I or II breast cancer. Ann Surg Oncol 2004, 11:1018-24.

12. Schrenk P, Rieger R, Shamiyeh A, Wayand W: Morbidity following sentinel lymph node biopsy versus axillary lymph node dissection for patients with breast carcinoma. Cancer 2000, 88:608-14.

13. Kuerer HM, Sahin AA, Hunt KK, Newman LA, Breslin TM, Ames FC, Ross MI, Buzdar AU, Hortobagyi GN, Singletary SE: Incidence and impact of documented eradication of breast cancer axillary lymph node metastases before surgery in patients treated with neoadjuvant chemotherapy. Ann Surg 1999, 230:72-8.

14. Mamounas EP, Brown A, Anderson S, Smith R, Julian T, Miller B, Bear HD, Caldwell CB, Walker AP, Mikkelson WM, Stauffer JS, Robidoux A, Theoret H, Soran A, Fisher B, Wickerham DL, Wolmark N: Sentinel node biopsy after neo-adjuvant chemotherapy in chemotherapy in breast cancer: results from NSABP protocol B-27. J Clin Oncol 2005, 23:2694-702.

15. Xing Y, Foy M, Cox DD: Meta-analysis of sentinel lymph node biopsy after preoperative chemotherapy in patients with breast cancer. $\mathrm{Br} J$ Surg 2006, 93:539-46.

16. Krag D, Weaver D, Ashikaga T, Moffat F, Klimberg VS, Shriver C, Feldman S, Kusminsky R, Gadd M, Kuhn J, Harlow S, Beitsch P: The sentinel node in breast cancer-a multicenter validation study. N Engl J Med 1998, 339:941-6.

17. Tafra L, Lannin DR, Swanson MS, Tafra L, Lannin DR, Swanson MS, Van Eyk JJ, Verbanac KM, Chua AN, Ng PC, Edwards MS, Halliday BE, Henry CA, Sommers LM, Carman CM, Molin MR, Yurko JE, Perry RR, Williams R, et al: Multicenter trial of sentinel node biopsy for breast cancer using both technetium sulfur colloid and isosulfan blue dye. Ann Surg 2001, 233:51-59.

18. McMasters KM, Tuttle TM, Carlson DJ, Brown CM, Noyes RD, Glaser RL, Vennekotter DJ, Turk PS, Tate PS, Sardi A, Cerrito PB, Edwards MJ: Sentinel lymph node biopsy for breast cancer: a suitable alternative to routine axillary dissection in multi-institutional practice when optimal technique is used. J Clin Oncol 2000, 18:2560-6.

19. Tanis PJ, Nieweg OE, Hart AA, Kroon BB: The illusion of the learning phase for lymphatic mapping. Ann surg Oncol 2002, 9:142-7.

20. Breslin TM, Cohen L, Sahin A, Fleming JB, Kuerer HM, Newman LA, Delpassand ES, House R, Ames FC, Feig BW, Ross MI, Singletary SE, Buzdar AU, Hortobagyi GN, Hunt KK, et al: Sentinel lymph node is accurate after neoadjuvant chemotherapy for breast cancer. J Clin Oncol 2000, 18:3480-3486.

21. Nason KS, Anderson BO, Byrd DR, Dunnwald LK, Eary JF, Mankoff DA, Livingston R, Schmidt RA, Jewell KD, Yeung RS, Moe RE: Increased false negative sentinel node biopsy rates after preoperative chemotherapy for invasive breast carcinoma. Cancer 2000, 89:2187-2194.

22. Julian TB, Patel N, Dusi D, Olson P, Nathan G, Jasnosz K, Isaacs $G$, Wolmark N: Sentinel lymph node biopsy after neoadjuvant chemotherapy for breast cancer. Am J surg 2001, 182:407-410.

23. Fernández $A$, Cortés $M$, Benito E, Azpeitia D, Prieto L, Moreno A, Ricart $Y$, Mora J, Escobedo A, Martín Comín J: Gamma probe sentinel node localization and biopsy in breast cancer patient treated with a neoadjuvant chemotherapy scheme. Nucl Med Commun 2001, 22:361-366.

24. Stearns V, Ewing CA, Slack R, Penannen MF, Hayes DF, Tsangaris TN: Sentinel lymphadenopathy after neoadjuvant chemotherapy for breast cancer may reliably represent the axilla except for inflammatory breast carcinoma. Ann Surg Oncol 2002, 9:235-242.

25. Haid A, Tausch C, Lang A, Lutz J, Fritzsche H, Peschina W, Breitfellner G, Sega W, Aufschnaiter M, Sturn H, Zimmermann G: Is sentinel lymph node biopsy reliable and indicated after preoperative chemotherapy in patients with breast carcinoma? Cancer 2001, 92(5):1080-4. 
26. Miller AR, Thomason VE, Yeh IT, Alrahwan A, Sharkey FE, Stauffer J, Otto PM, McKay C, Kahlenberg MS, Phillips WT, Cruz AB Jr: Analysis of sentinel lymph node mapping with immediate pathologic review in patients receiving preoperative chemotherapy for breast carcinoma. Ann Surg Oncol 2002, 9:243-247.

doi:10.1186/1477-7819-9-19

Cite this article as: Chintamani et al:: Sentinel lymph node biopsy using dye alone method is reliable and accurate even after neo-adjuvant chemotherapy in locally advanced breast cancer - a prospective study. World Journal of Surgical Oncology 2011 9:19.

Submit your next manuscript to BioMed Central and take full advantage of:

- Convenient online submission

- Thorough peer review

- No space constraints or color figure charges

- Immediate publication on acceptance

- Inclusion in PubMed, CAS, Scopus and Google Scholar

- Research which is freely available for redistribution

Submit your manuscript at www.biomedcentral.com/submit
() Biomed Central 